\title{
Radionuclide-embedded gold nanoparticles for enhanced dendritic cell-based cancer immunotherapy, sensitive and quantitative tracking of dendritic cells with PET and Cerenkov luminescence
}

\author{
Sang Bong Lee ${ }^{1,6}$, Su Bi Ahn ${ }^{1,6}$, Sang-Woo Lee ${ }^{1}$, Shin Young Jeong1, Yoon Ghilsuk ${ }^{2}$, Byeong-Cheol Ahn ${ }^{1}$, \\ Eun-Mi Kim ${ }^{3}$, Hwan-Jeong Jeong ${ }^{3}$, Jaetae Lee ${ }^{1,4}$, Dong-Kwon Lim $^{5}$ and Yong Hyun Jeon ${ }^{1}$
}

Radionuclide-embedded gold nanoparticles (Rle-AuNPs) were developed as a highly sensitive and stable nuclear and optical imaging agent for efficient dendritic cell (DC)-based immunotherapy and sensitive tracking of DC-migration to lymph nodes. The Rle-AuNPs were synthesized via simple and straightforward DNA-based radiolabeling chemistry and additional Au shell formation strategies, leading to high radiosensitivity and excellent in vivo stability. The Rle-AuNPs exert no adverse effects on the biological functions of DCs, and labeled DCs show strong antitumor immunity for lung cancer. Furthermore, the high radiosensitivity of the Rle-AuNPs allows for sensitive and long-term monitoring of DC migration to draining lymph nodes. The developed Cerenkov radiation-based optical imaging approach provides quantitative and sensitive results comparable with that of positron emission tomography imaging. These results highlight the strong potential of the Rle-AuNPs as a highly sensitive and stable nuclear and optical imaging platform for future bioimaging application such as cell tracking and tumor imaging.

NPG Asia Materials (2016) 8, e281; doi:10.1038/am.2016.80; published online 17 June 2016

\section{INTRODUCTION}

Gold nanoparticle (AuNP)-based imaging agents have been extensively investigated because of their advantageous properties such as biocompatibility, unique optical properties, simple surface chemistry for targeting and surface passivation. ${ }^{1-3}$ Highly sensitive imaging agents can greatly reduce the required effective dose for bioimaging, and consequently reduce possible side effects. Protection of radioisotopes on the nanoparticles is crucial for maintaining sensitivity of the imaging agent for a long time in vivo. Therefore, simple, straightforward labeling chemistry that can produce sensitive imaging agents and robust protection methods have been intensively sought. ${ }^{4-7}$ Non-covalent conjugation of ${ }^{125} \mathrm{I}$ on AuNPs resulted in a low loading of radio-isotopes per particle (only six iodines per particle) and release of the radio-isotope from the AuNP surface was also significant in spite of the presence of a protective layer composed of a polymer (that is, PEG), which necessitated the injection of a high dose $\left(10 \mathrm{mg} \mathrm{kg}^{-1}\right)$ of the imaging agent. $^{8}$
Although the signal sensitivity and stability of bioimaging agents are critical issues for all molecular imaging modalities, in the field of dendritic cell (DC)-based cancer immunotherapy, achieving sensitive tracking of the migration of bone marrow-derived DCs to vascular and lymphatic systems is especially important for accurately evaluating the outcomes of DC-based immunotherapy. ${ }^{9-13}$ A number of DC-tracking methods for visualization of lymph nodes via nuclear (that is, positron emission tomography (PET), single-photon emission computed tomography (SPECT)), magnetic resonance ${ }^{14}$ and optical imaging (that is, quantum dots, organic fluorophores and upconversion luminescent nanoparticles ${ }^{15}$ ) have been developed; nevertheless, sensitive and long-term tracking of DCs is challenging because of sensitivity and stability issues associated with imaging agents in vivo state. ${ }^{16}$

While nuclear imaging with PET or SPECT is routinely employed in clinical nuclear medicine due to the high sensitivity (SPECT: $10^{-10} \mathrm{M}$, PET: $10^{-11}-10^{-12} \mathrm{M}$ ) and the absence of depth limitation of these techniques, ${ }^{17}$ developing an optical-based imaging modality that is

${ }^{1}$ Department of Nuclear Medicine, Kyungpook National University School of Medicine, Leading-edge Research Center for Drug Discovery and Development for Diabetes and Metabolic Disease, Kyungpook National University Hospital, Daegu, South Korea; ${ }^{2}$ Department of Pathology, School of Medicine, Kyungpook National University, Daegu, South Korea; ${ }^{3}$ Department of Nuclear Medicine, Chonbuk National University, Jeonju, South Korea; ${ }^{4}$ Daegu-Gyeongbuk Medical Innovation Foundation, Daegu, South Korea and ${ }^{5}$ KU-KIST Graduate School of Converging Science and Technology, Korea University, Seongbuk-gu, Seoul, South Korea

Correspondence: Professor J Lee or Professor YH Jeon, Department of Nuclear Medicine, Kyungpook National University School of Medicine, Leading-edge Research Center for Drug Discovery and Development for Diabetes and Metabolic Disease, Kyungpook National University Hospital, Daegu 702-210, South Korea.

E-mail: jaetae@knu.ac.kr or jeon9014@gmail.com

or Professor D-K Lim, KU-KIST Graduate School of Converging Science and Technology, Korea University, 145 Anam-ro, Seongbuk-gu, Seoul 02481, South Korea.

E-mail: dklim@korea.ac.kr

${ }^{6}$ These authors contributed equally to this work.

Received 12 November 2015; revised 15 April 2016; accepted 30 April 2016 
comparable to nuclear imaging in terms of sensitivity and penetration depth would be greatly beneficial for achieving cost-effective and highly sensitive optical imaging. ${ }^{18}$ In this regard, Cerenkov luminescence imaging (CLI) is a promising optical-based method based on the unique property of photo-emission from luminescent radionuclides when the charged particles $\left(\right.$ mostly $\beta^{+}$) travel through water with velocities faster than the speed of light. ${ }^{18,19}$ In spite of many attempts to use PET radionuclides, such as ${ }^{64} \mathrm{Cu},{ }^{68} \mathrm{Ga}$ and ${ }^{124} \mathrm{I}$ for CLI-based optical imaging, ${ }^{20}$ the quantitative relationship between PET and CLI imaging has not yet been firmly established, though such knowledge is required for future CLI-based imaging in clinical applications.

Herein, we report a simple and straightforward synthetic scheme for producing gold-based imaging agents that are applicable as a dual bio-imaging modality by combining nuclear imaging and CLI. The multivalent adenine-rich oligonucleotide sequences on the AuNPs enable conjugation of high numbers of radio-isotopes per AuNP. The additional $\mathrm{Au}$ shell produces a stable protective layer that can completely prevent enzymatic attack in biological systems. Because of the high radio-sensitivity of the RIe-AuNPs, only a small dose of Au $\left(0.3 \mathrm{mg} \mathrm{kg}^{-1}\right)$ is required to obtain acceptable PET and CLI images. Furthermore, the RIe-AuNPs show no adverse effects on the biological functions of DCs, and a strong and enhanced antitumor immune response against lung cancer is demonstrated. The strong radioactivity of the RIe-AuNPs also enables sensitive monitoring of the migration of DCs to the lymph nodes using PET and CLI simultaneously. Further in vivo studies with i.v. injection show that the CLI-based images are comparable with the corresponding PET images because of the strong CLI from the RIe-AuNPs (Scheme 1).

\section{EXPERIMENTAL PROCEDURES}

\section{Materials}

All chemical reagents were purchased from Sigma-Aldrich (St Louis, MO, USA). Citrate-stabilized AuNPs $(20 \mathrm{~nm})$ were purchased from Ted Pella (Redding, CA, USA). Sulfosuccimidyl-3-[4-hydroxyphenyl]propionate (sulfo-SHPP) was purchased from Thermo Scientific (Rockford, IL, USA). Radioactive sodium iodide $\left(\mathrm{Na}^{125} \mathrm{I}\right)$ was purchased from Perkin Elmer (Waltham, MA, USA), and radioactive sodium iodide $\left(\mathrm{Na}^{124} \mathrm{I}\right)$ was provided by Duchem Bio (Daegu, South Korea) and KIRAMS (Seoul, South Korea). Bone marrow-derived DCs, generated by the differentiation of bone marrow cells, were used for all experiments. ${ }^{21}$ Murine Lewis lung carcinoma (LLC) cells and cervical cancer cells were cultured in complete Dulbecco's modified Eagle medium (HyClone, Logan, UT, USA) supplemented with $10 \%$ heat-inactivated fetal bovine serum (HyClone), $50 \mu \mathrm{g} \mathrm{ml}^{-1}$ gentamicin (Gibco, Grand Island, NY, USA) and $1.0 \%$ penicillin-streptomycin (Gibco). Specific pathogen-free, 6-week-old, immunocompetent C57BL/6 mice obtained from SLC (Shizuoka, Japan) were used for the experiments. All animal experimental procedures were conducted in strict accordance with the appropriate institutional guidelines for animal research. The protocol was approved by the Committee on the Ethics of Animal Experiments of the Kyungpook National University (approval number: KNU 2012-43).

\section{Preparation of RIe-AuNPs}

Freshly reduced thiolated adenine-rich oligonucleotides ( $\left.3^{\prime}-\mathrm{HS}-\left(\mathrm{CH}_{2}\right)_{3}-\mathrm{A}_{10}-5^{\prime}\right)$ were appended to citrate-AuNPs $(20 \mathrm{~nm})$ using the standard salt aging procedures. ${ }^{22}$ The amine groups of the adenine-rich oligonucleotides on the AuNPs $\left(\mathrm{A}_{10}\right.$-AuNPs) were then modified with sulfo-SHPP for conjugation with radioisotopes such as sodium iodide $\left(\mathrm{Na}^{125} \mathrm{I}\right.$ or $\mathrm{Na}^{124} \mathrm{I}$ ) (Supplementary Figure S1). To prepare $20 \mathrm{ml}$ of SHPP-modified AuNPs (1.0 nM), a freshly prepared $\mathrm{A}_{10}$-AuNP solution $(20 \mathrm{ml})$ was reacted with sulfo-SHPP $(1.0 \mathrm{mg})$ for $12 \mathrm{~h}$ at room temperature and then purified via centrifugation (12 000 r.p.m./ $15 \mathrm{~min}$ ). The supernatant was removed and the precipitates were redispersed in distilled water $(20 \mathrm{ml})$. The particle concentration was determined by using a ultraviolet (UV)-visible spectrophotometer. For radioisotope labeling, the SHPP-AuNPs ( $1 \mathrm{ml}$ of $1.0 \mathrm{~nm}$ ) were reacted with $150 \mu \mathrm{l}$ of $\mathrm{Na}^{125} \mathrm{I}$ $(129.5 \mathrm{MBq})$ or $\mathrm{Na}^{124} \mathrm{I}(81.4 \mathrm{MBq})$ in the presence of $90 \mu \mathrm{l}$ of chloramine-T $\left(3 \mathrm{mg} \mathrm{ml}^{-1}\right)$ and $100 \mu \mathrm{l}$ of $1 \%$ sodium dodecyl sulfate for $2 \mathrm{~h}$ at room temperature and then purified by centrifugation (12 000 r.p.m./15 min). The supernatant was removed and the precipitates were redispersed in distilled water. The decay-corrected radiochemical yield was found to be $90-95 \%$ $\left(\mathrm{Na}^{125} \mathrm{I}\right.$ (116.5-118.4 MBq), Na ${ }^{124} \mathrm{I}$ (73.2-74 MBq). Subsequently, RIe-AuNPs with ${ }^{125} \mathrm{I}$ or ${ }^{124} \mathrm{I}$ were prepared by mixing $1 \mathrm{ml}$ of RI-AuNPs (1.0 nM) with $500 \mu \mathrm{l}$ of $1.0 \%(\mathrm{w} / \mathrm{v})$ poly $\left(N\right.$-vinyl-2-pyrrolidone) solution $\left(M_{w} 40 \mathrm{kDa}\right)$, followed by addition of $100 \mu \mathrm{l}$ of $100 \mathrm{~mm}$ phosphate buffer ( $\mathrm{pH}$ 7.4) and $165 \mu \mathrm{l}$ of $2.0 \mathrm{M} \mathrm{NaCl}$. Finally, the solution was reacted with $434 \mu \mathrm{l}$ hydroxylamine hydrochloride (10 mm) and $434 \mu \mathrm{l} \mathrm{HAuCl}_{4}(5 \mathrm{~mm})$. The reaction mixtures were gently vortexed for $30 \mathrm{~min}$ at room temperature and then purified by centrifugation (6000 r.p.m./15 min). The supernatant was removed and the precipitates were redispersed in distilled water $(1 \mathrm{ml})$ (Figure 1 and Supplementary Figure S1).

\section{Characterization of RIe-AuNPs}

Analyses of the dispersity in water, chemical composition and structure of the prepared RIe-AuNPs were performed via UV-visible spectrophotometry, X-ray

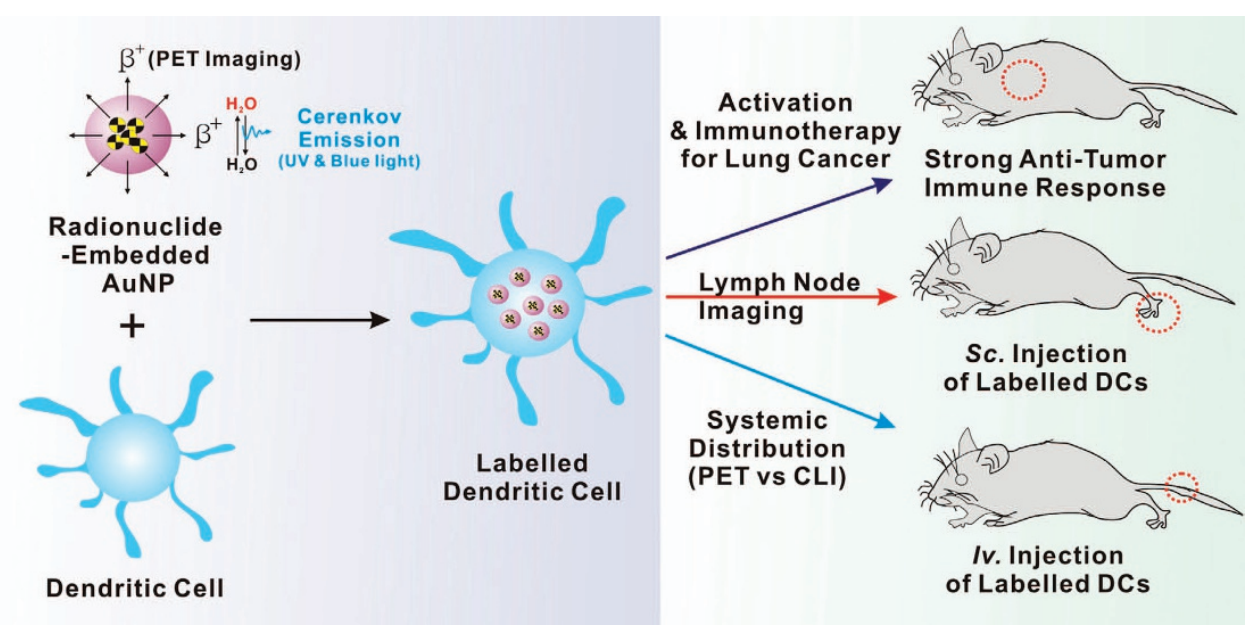

Scheme 1 Dendritic cell labeling with radionuclide-embedded AuNP (Rle-AuNP), cancer immunotherapy and PET/Cerenkov emission-based tracking in vivo. PET, positron emission tomography. 
a

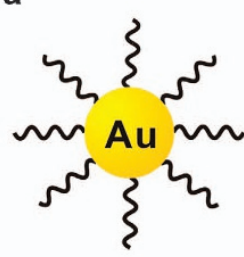

$A_{10}$-AuNP

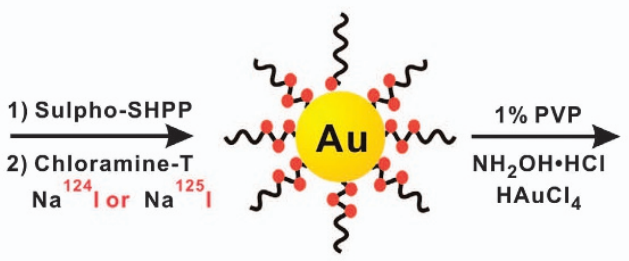

Radionuclide-modified AuNP (RI-AuNP)

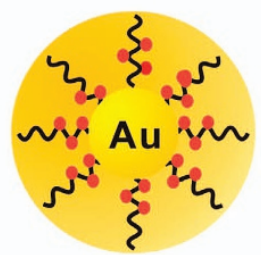

Radionuclide-embedded AuNP (Rle-AuNP)

b

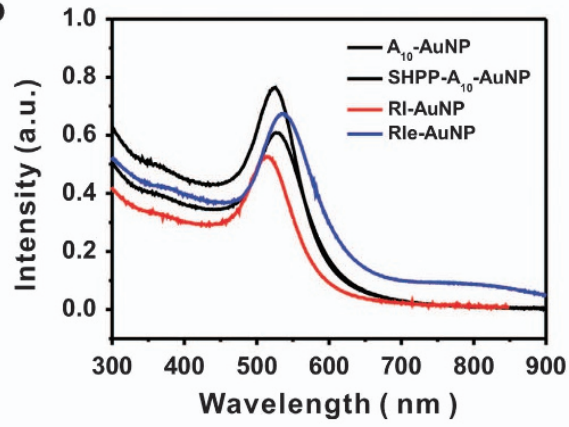

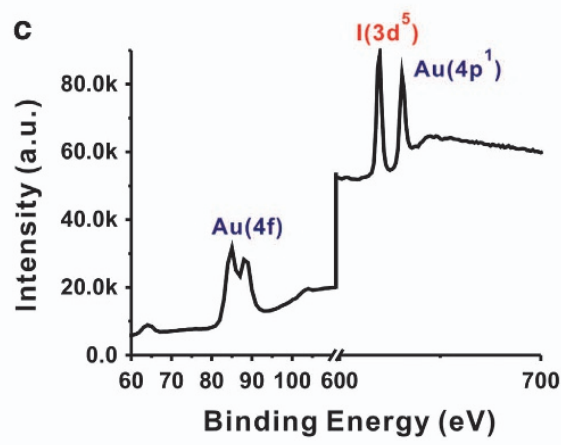

d

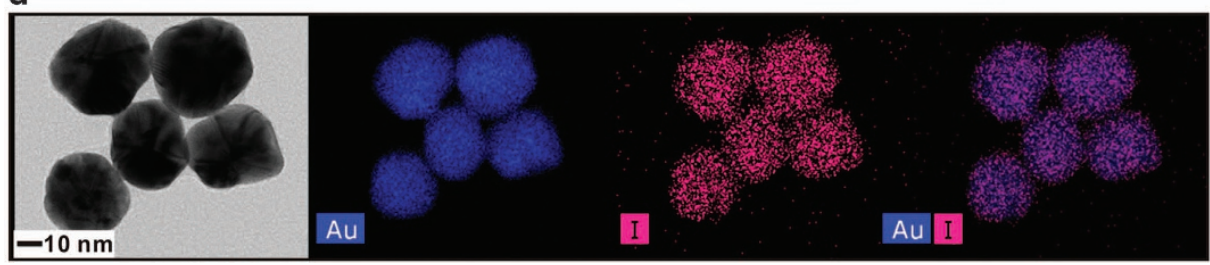

Figure 1 Synthetic scheme and characterization of radionuclide-embedded gold nanoparticles (Rle-AuNPs). (a) Schematic of synthesis of Rle-AuNPs. (b) UV-visible spectra of $\mathrm{A}_{10}$-AuNPs, SHPP-A $A_{10}$-AuNPs, RI-AuNPs (red line) and radionuclide-embedded AuNPs (Rle-AuNPs, blue line). (c) X-ray photoelectron spectroscopy (XPS) data for Rle-AuNPs. (d) Transmission electron microscopy (TEM) images of Rle-AuNPs and energy dispersive X-ray (EDX)-based elemental mapping for Au (blue), iodine (red), and merged Au and iodine. UV, ultraviolet.

photoelectron spectroscopy, energy dispersive X-ray-based elemental mapping and transmission electron microscopy (Figure 1).

\section{Radio-sensitivity and in vitro stability}

The changes in the SPECT and PET signal intensity with varying concentrations of the RIe-AuNPs (1.0 pm-0.5 nм) were investigated by using a gamma counter (Gamma-10; Sinjin Medics, Goyang-Si, South Korea) (Figure 2 and Supplementary Figure S2). For the in vitro stability test, the RI-AuNPs $(100 \mu \mathrm{l}, 1.0 \mathrm{~nm})$ and RIe-AuNPs $(100 \mu \mathrm{l}, 1.0 \mathrm{~nm})$ were incubated with human serum $(900 \mu \mathrm{l})$ at $37^{\circ} \mathrm{C}$; the released radio-isotopes were then quantified via thin layer chromatography (eluent: acetone) and the results were recorded using a scanner (AR-2000; Bioscan, Hopkinton, MA, USA) (Figure 2).

\section{Uptake efficiency and cytotoxicity of RIe-AuNPs in DCs}

The RIe-AuNPs were diluted in the cell culture medium at various concentrations ranging from 0.5 to $4.0 \mathrm{~nm}$ and incubated with DCs for $3 \mathrm{~h}$ at $37^{\circ} \mathrm{C}$. After incubation, the DCs were washed with phosphate buffer and centrifuged (1300 r.p.m./5 min) twice to remove free RIe-AuNPs in the supernatant. The uptake efficiency of the RIe-AuNPs in the DCs was measured with a gamma counter (Gamma-10). The time-dependent uptake efficiency was studied using a $2.0 \mathrm{~nm}$ concentration of the RIe-AuNPs (Supplementary Figure S3). Time-dependent changes of the radioactivity in the DCs were determined by measuring the radioactivity of the supernatant over time (Figure 2 and Supplementary Figure S4). Cell proliferation assay was performed by using 3-(4,5-dimethylthiazol-2-yl)-2,5-diphenyltetrazolium bromide (Dojindo Laboratories, Tokyo, Japan) to evaluate the cytotoxicity of the RIe-AuNPs in the DCs. Apoptosis analysis was conducted with FITC-conjugated Annexin V and propidium iodide (BD Biosciences, San Jose,
CA, USA) using a flow cytometer (Accuri C6, BD Biosciences) (Supplementary Figure S5).

\section{Biological functions of DCs}

Phenotype marker analysis. Unlabeled DCs or DCs labeled with the RIe-AuNPs (2.0 nM) were stained with phycoerythrin-conjugated CD11c, $\mathrm{H}-2 \mathrm{~Kb}$ (MHC-I) or I-A/I-E (MHC-II), CD86, and CD54, AllophycocyaninCy7-conjugated CD197 (CCR-7) antibody (BD Bioscience) at $4{ }^{\circ} \mathrm{C}$ for $30 \mathrm{~min}$. The washed cells were analyzed using flow cytometry. Isotype-matched monoclonal antibodies were used as controls. The data were analyzed using FlowJo analysis software (FlowJo, Ashland, OR, USA) (Supplementary Figure S6).

Cytokine assay. Immature DCs were stimulated with lipopolysaccharide $\left(1.0 \mu \mathrm{g} \mathrm{ml}^{-1}\right)$ for $12 \mathrm{~h}$. Mature DCs labeled with RIe-AuNPs or unlabeled mature DCs were seeded in a culture plate. After $24 \mathrm{~h}$, the amount of TNF- $\alpha$ and IL-6 in the supernatant was quantified with a multiplexed bead-based immunoassay (BD Cytometric Bead Array) system and flow cytometry (BD Biosciences) (Supplementary Figure S7).

Transwell migration assay. The DCs were incubated with $1.0 \mu \mathrm{g} \mathrm{ml}^{-1}$ prostaglandin $\mathrm{E}_{2}$ (Sigma) for $24 \mathrm{~h}$, and culture medium containing CCL19 (PeproTech) was then added to the lower chamber, followed by addition of $2 \times 10^{5}$ cells to the upper chamber containing polycarbonate membranes with $5-\mu \mathrm{m}$ pores (BD Falcon). After incubating for $2 \mathrm{~h}$ at $37^{\circ} \mathrm{C}$, the cells migrating to the bottom chamber were collected and counted by flow cytometry. Events occurring over a fixed time period (60 s) were analyzed using FlowJo analysis software. 
a
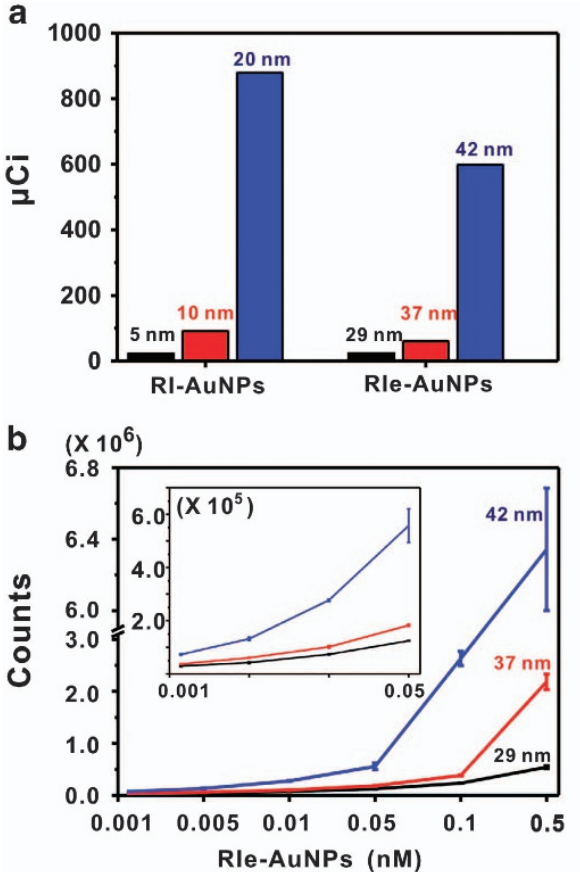

C

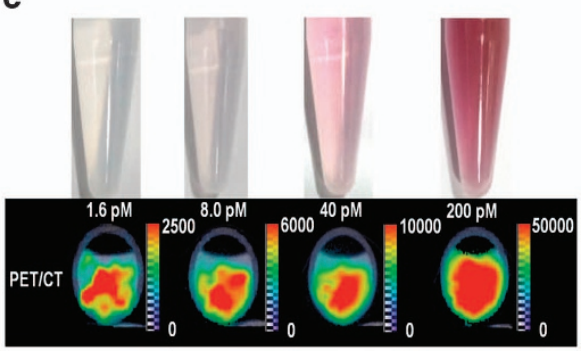

d

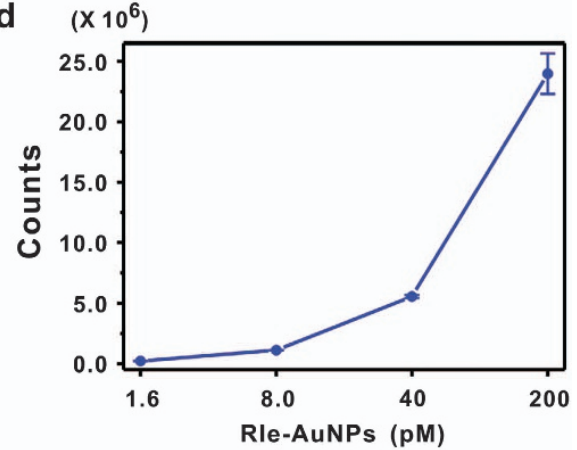

e
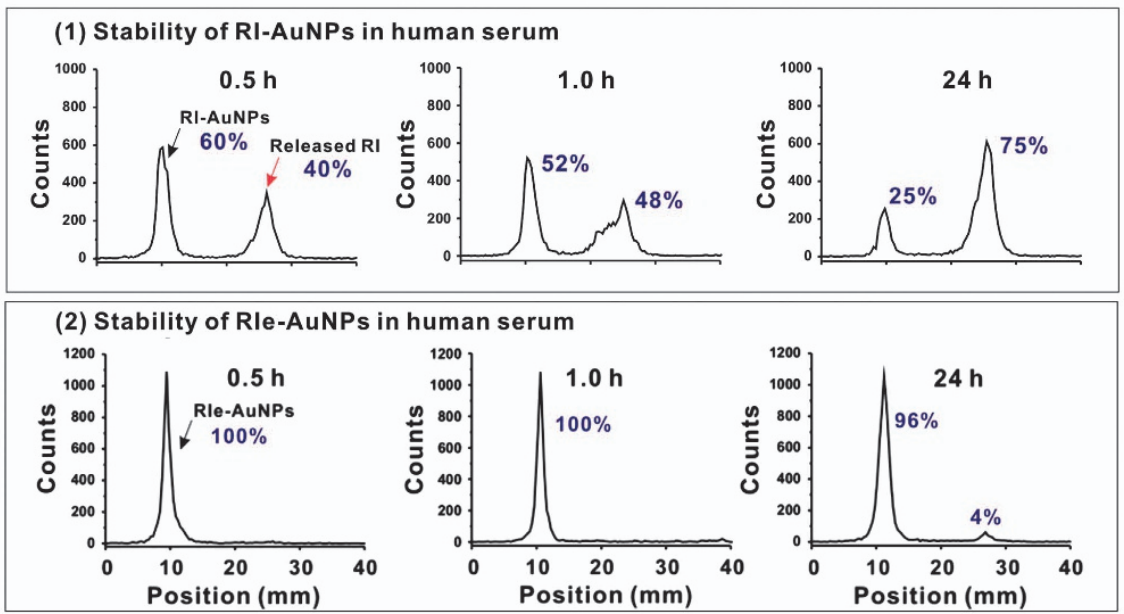

Figure 2 Radioactivity of Rle-AuNPs as a function of core particle size and concentration and stability of RI-AuNPs and Rle-AuNPs in human serum. (a) Radioactivity of Rle-AuNPs $\left({ }^{125} \mathrm{l}\right)$ as a function of core particle size ( $5 \mathrm{~nm}$ (black), $10 \mathrm{~nm}$ (red) and $20 \mathrm{~nm}$ (blue) for the core DNA-AuNP). (b) Sensitivity of Rle-AuNPs $(125 \mathrm{l})$ as a function of concentration ( $1.0 \mathrm{pm}$ to $0.5 \mathrm{~nm}$ ). (c) Photographs of the Rle-AuNP (124I) solution and PET/CT images. (d) Sensitivity of Rle-AuNPs $\left({ }^{124} \mathrm{I}\right)$ as a function of concentration (1.6-200 pm). (e) Time-dependent stability of RI-AuNPs (124I) (1) and Rle-AuNPs (2) in human serum at $37^{\circ} \mathrm{C}$. (number (blue) indicate relative area \% of peaks). CT, computed tomography; PET, positron emission tomography; Rle-AuNP, radionuclide-embedded gold nanoparticle.

Antigen uptake efficiency. Unlabeled DCs or DCs labeled with the RIe-AuNPs were incubated with $100 \mu \mathrm{g} \mathrm{ml}^{-1}$ Texas Red-ovalbumin (Life Technologies, Grand Island, NY, USA) at $37^{\circ} \mathrm{C}$ for $1 \mathrm{~h}$. After labeling, the cells were washed with phosphate-buffered saline and analyzed using a BD Accuri C6 flow cytometer.

In vivo DC-based cancer immunotherapy

As illustrated in Supplementary Figure 58 , the mice $(N=7)$ were divided into four groups based on the treatment regimen: (1) unlabeled and non-pulsed DCs, (2) unlabeled DCs pulsed with LLC lysates, (3) labeled and non-pulsed DCs and (4) labeled DCs pulsed with LLC lysates. For pulsing of DCs, total LLC lysates were prepared with repetitive freezing and thawing and then prepared LLC cell lysates $\left(5-10 \mu \mathrm{g} \mathrm{ml}^{-1}\right)$ were treated to DCs overnight.
The mice were i.m. injected with appropriate preparations of DCs once a week for 2 weeks. One week after final vaccination, LLC cells were s.c. injected into the mice, and tumor growth was monitored with palpation and ${ }^{18} \mathrm{~F}$-fludeoxyglucose $\left({ }^{18} \mathrm{~F}-\mathrm{FDG}\right) \mathrm{PET} / \mathrm{CT}$ at the indicated times. The tumor volume $\left(\mathrm{mm}^{3}\right)$ was calculated as $\left(A \times B^{2}\right) / 2$, where $A$ is the long diameter and $B$ is the short diameter (Supplementary Figure S9).

For cytotoxic T lymphocyte assay, splenocytes harvested from tumor-bearing mice were restimulated with total LLC lysates and IL-2 for 4 days. LLC/effluc cells were used as target cells. The target cells were seeded in black, clear-bottomed 96-well plates $\left(1 \times 10^{4}\right.$ cells). After overnight incubation, splenocytes as effectors were added into the wells containing the target cells at an effector to target ratio of 10:1. Eleven hours later, the luciferase activity was measured with an IVIS Lumina III instrument (Perkin Elmer). 


\section{In vivo PET imaging and CLI}

For lymph node imaging, the mice $(N=5)$ initially received $30 \mathrm{ng}$ TNF- $\alpha$ via s. c. injection into the hind footpads, then on day 1 RIe-AuNP-labeled DCs $(50 \mu \mathrm{l}$ of cells per mouse $\left(3 \times 10^{6}\right.$ cells, $\left.\left.6.44 \mu \mathrm{g}(\mathrm{Au}), 0.2 \mathrm{mg} \mathrm{kg}^{-1}\right)\right)$ were s.c. injected into the footpads, and PET/CT imaging was performed at the indicated times (Supplementary Figure S10). In vivo experiments were performed in triplicate.

For quantitative comparison of PET and CLI, the RIe-AuNP-labeled DCs $\left(50 \mu \mathrm{l}\right.$ of cells per mouse $\left(3 \times 10^{6}\right.$ cells, $\left.\left.6.44 \mu \mathrm{g}(\mathrm{Au}), 0.2 \mathrm{mg} \mathrm{kg}^{-1}\right)\right)$ were administered via tail vein injection, and PET/CT imaging was performed at the indicated times. For PET/CT imaging, $20 \mathrm{~min}$ scans (DC imaging) were performed with the Triumph II PET-CT system (LabPET8; Gamma Medica-Ideas, Waukesha, WI, USA). CT scans were performed with an $\mathrm{X}$-ray detector immediately following acquisition of the PET images. The PET images were reconstructed by three-dimensional OSEM iterative image reconstruction, and the CT images were reconstructed using filtered back-projections. All mice were anesthetized using 1-2\% isoflurane gas during imaging. PET images were co-registered with anatomical CT images using three-dimensional image visualization and analysis software (VIVID; Gamma Medica-Ideas, Northridge, CA, USA). To measure the uptake (\%ID/cc) for the volumes of interest, the volumes of interest from each image were manually segmented from coregistered CT images using both VIVID and PMOD software (PMOD Technologies, Zurich, Switzerland), and the uptake in the region-of-interest was measured with PMOD 3.5 software.

CLI was performed using the IVIS Lumina III imaging system. Grayscale photographic images and bioluminescent color images were superimposed using LIVINGIMAGE (version 2.12, Perkin Elmer) and IGOR Image Analysis FX software (WaveMetrics, Lake Oswego, OR, USA). CLI signals were expressed in units of photons per $\mathrm{cm}^{2}$ per second per steradian (P per $\left.\mathrm{cm}^{2} \mathrm{~s}^{-1} \mathrm{sr}^{-1}\right)$

\section{Biodistribution study and ex vivo imaging}

Mice $(N=5)$ were killed at the indicated times after administration of the labeled DCs via the footpads or tail vein. Organs of interest were removed, weighed and analyzed for radioactivity using a gamma counter. The results are expressed as the percentage of the dose injected per gram of tissue (\%ID per g). After image acquisition, the mice were killed, and the draining popliteal lymph node (DPLN) was excised. The respective excised lymph nodes were placed in tubes, and ex vivo PET/CT imaging was performed for $5 \mathrm{~min}$. In vivo experiments were performed in triplicate.

\section{Histological data and immunohistochemistry}

Histological data were obtained from draining and non-draining lymph nodes (formalin-fixed, paraffin-embedded) and were analyzed based on microscopic review of the hematoxylin and eosin (H\&E)-stained slides. Immunohistochemical staining using a Benchmark XT slide stainer (Ventana Medical Systems, Tucson, AZ, USA) was performed in accordance with the manufacturer's instructions. Anti-CD3 (1:200 dilution; clone SP7; Thermo Fisher Scientific, Waltham, MA, USA), anti-CD79a (prediluted; clone SP18; Ventana Medical Systems) and anti-S-100 (1:400 dilution; clone B-8; Dako, Glostrup, Denmark) were applied to whole-sectioned slides of the lymph nodes.

\section{RESULTS AND DISCUSSION}

Synthesis of RIe-AuNPs

Oligonucleotide-modified AuNPs have been extensively investigated as a highly sensitive biosensor or gene delivery platform based on the high loading capability per nanoparticle. ${ }^{4,23,24}$ In this study, we focused on the chemical functionality of the oligonucleotide base on the AuNPs that can be used as a reaction site for radiolabeling. The primary amine group in the adenine base can be functionalized with sulfo-SHPP, leading to the formation of an amide bond between the 4-hydroxy phenyl group and primary amine in adenine (Supplementary Figure S1). The 2,5-positions of the 4-hydroxy phenyl ring are possible sites for facile iodination with $\mathrm{Na}^{124} \mathrm{I}$ or $\mathrm{Na}^{125} \mathrm{I}$. The multiple adenine bases in a single oligonucleotide and the multiple oligonucleotide strands per AuNP ${ }^{22}$ provide numerous reactive sites for iodination. For example, when the $20 \mathrm{~nm}$ AuNPs were modified with thiolated oligonucleotides composed of tens of adenine bases $\left(A_{10}\right), 2000$ iodine molecules could be appended to each AuNP because there are 20 reactive sites per $A_{10}$-oligo strand and $100 A_{10}$ oligo strands per AuNP. Therefore, the use of adenine-rich DNA-modified AuNPs $\left(\mathrm{A}_{10}\right.$-AuNPs $)$ may be a promising strategy for improving the iodine loading on the AuNPs. ${ }^{25}$ Furthermore, the additional gold shell can greatly improve the in vivo stability of the radiolabeled DNA on the AuNPs by embedding radioisotopes with a gold shell to prevent possible cleavage by enzymes or other factors present in living cells.

The iodination reaction was performed by introducing either $\mathrm{Na}^{124} \mathrm{I}$ or $\mathrm{Na}^{125}$ I into the SHPP-A 10 -AuNP solution to produce radionuclideAuNPs (RI-AuNPs; Figure 1a). The reaction was completed within $120 \mathrm{~min}$ as monitored using a radio-TLC (eluent: acetone) scanner (Supplementary Figure S1). After completion of the reaction, the solution was centrifuged to remove unreacted radioactive NaI. The radiochemical yield of the isotope labeling reaction was found to be 99\% (Supplementary Figure S1). An additional Au shell formation reaction was performed to produce the RIe-AuNPs using our previously reported procedures. ${ }^{4} \mathrm{We}$ used ${ }^{125} \mathrm{I}$ to characterize the stability of the RIe-AuNPs, and ${ }^{124} \mathrm{I}$ was selected for combined PET and CLI imaging. The UV-visible spectra of the SHPP-A $\mathrm{A}_{10}$-AuNPs and the RI-AuNPs were identical to that of the $\mathrm{A}_{10}$-AuNPs, as shown in Figure $1 \mathrm{~b}$, indicating that no significant particle aggregation occurred during the radionuclide labeling reaction. After formation of the $\mathrm{Au}$ shell, the RIe-AuNPs showed a characteristic absorption band at $540 \mathrm{~nm}$, indicative of a spherical shape (Figure 1b). The hydrodynamic radius increased slightly as a result of the modifications; the hydrodynamic radii of the $A_{10}$-AuNPs, RI-AuNPs and RIe-AuNPs were $29.3 \pm 0.8 \mathrm{~nm}, 41.2 \pm 1.1 \mathrm{~nm}$ and $65.7 \pm 1.2 \mathrm{~nm}$, respectively (data not shown). Two characteristic peaks corresponding to $\mathrm{Au}\left(4 f, 4 p^{1}\right)$ and iodine $\left(3 d^{5}\right)$ were observed in the X-ray photoelectron spectroscopy analysis (Figure 1c). The RIe-AuNPs had a spherical morphology, as observed in the transmission electron microscope images, and energy dispersive X-ray mapping clearly showed the distribution of iodine around the AuNPs (Figure 1d).

\section{SPECT and PET sensitivity and in vitro stability of RIe-AuNPs}

The radio-sensitivities for RI-AuNPs and RIe-AuNPs were extensively investigated. In case of ${ }^{125} \mathrm{I}$ detection by SPECT and the gamma counter (Figures $2 \mathrm{a}$ and b), the RI-AuNPs (5 and $10 \mathrm{~nm}$ core diameters) exhibited low radioactivity because of the low loading of thiolated DNA on the AuNPs. The RI-AuNPs (20-nm core diameter) showed the strongest radioactive signals. A good linear relationship between AuNP size and radioactivity was observed as shown in Supplementary Figure S2. The RIe-AuNPs obtained by formation of $\mathrm{Au}$ shell on the RI-AuNPs (5, 10, $20 \mathrm{~nm}$ core) exhibited slightly decreased but strong radioactivity (Figure 2a). The response of the gamma count of the RIe-AuNPs (42 nm diameter) as a function of the NP concentration ( $1.0 \mathrm{pm}-0.5 \mathrm{~nm}$ ) was linear (Figure $2 \mathrm{~b}$ ). The RIe-AuNPs were detectable even at $1.0 \mathrm{pm}$, with $1.0 \times 10^{5}$ counts (Figure $2 b$, inset). The number density of radioisotopes per AuNP was calculated to be 2681 iodine molecules per AuNP (see Supporting Information). In the case of ${ }^{124} \mathrm{I}$ detection by PET/CT (Figures $2 \mathrm{c}$ and d), although the solution had no observable color at an RIe-AuNP concentration of $1.6 \mathrm{pM}$, the PET/CT images of tube phantoms containing the RIe-AuNPs showed intense radioactivity signals (Figure 2c). In accordance with the PET/CT images of the tube phantoms, measurement of the radioactivity using the gamma counter also demonstrated good correlation between the concentration 


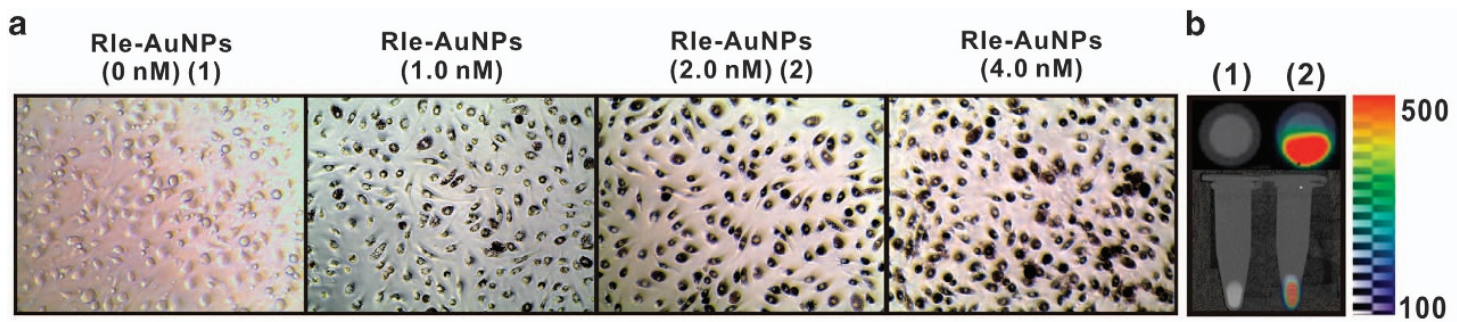

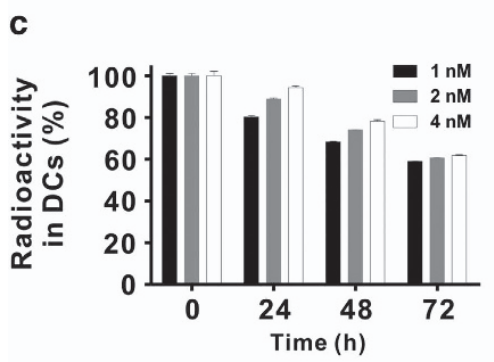

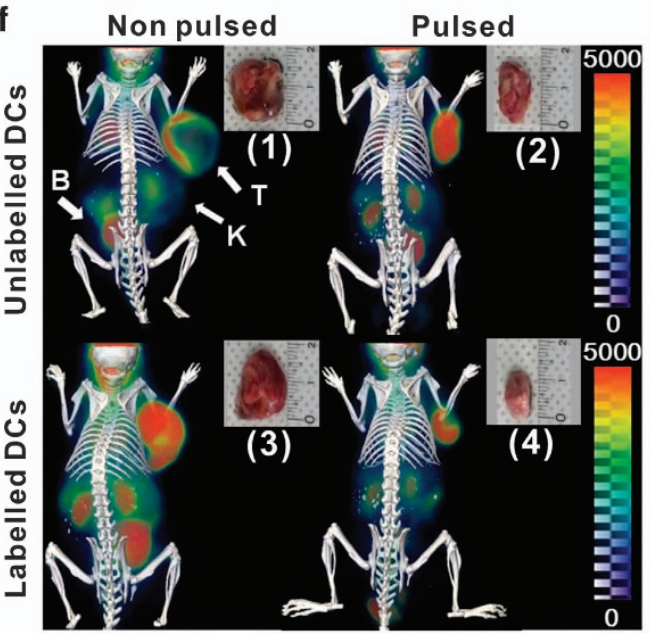

d

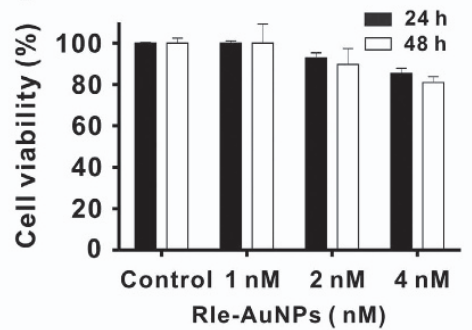

e Unlabelled DCs

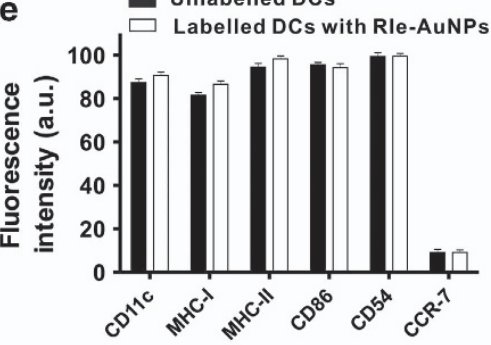

g

LLC
/effluc

(alone) (1) (2) (3) (4)
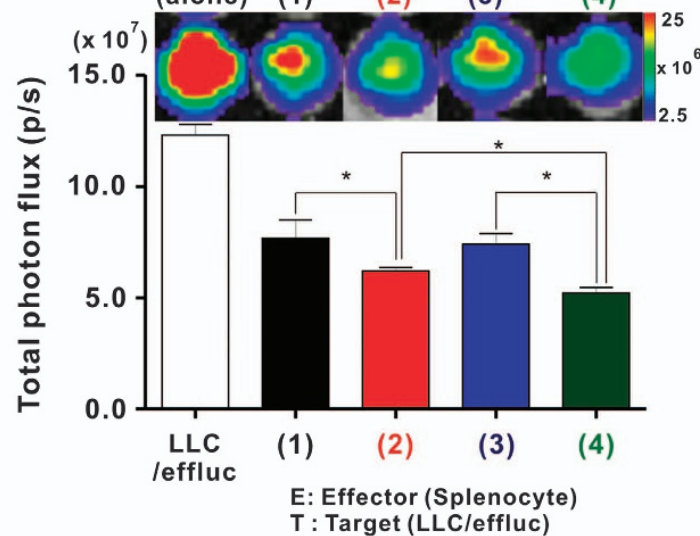

Figure 3 Uptake efficiency of Rle-AuNPs in DCs and its effects on the biological functions and antitumor immunity of DCs. (a) Bright-field images of DCs after incubation with three different concentrations of Rle-AuNPs (1.0-4.0 nm). (b) PET/CT images of tube phantom containing either unlabeled DCs (1) or labeled DCs (2). (c) The time-dependent radioactivity in DCs. (d) DC viability as a function of Rle-AuNP concentration (1.0-4.0 nm) and incubation time (24 h (black bar) or $48 \mathrm{~h}$ (empty bar)). (e) Expression of phenotype markers (CD11c, MHC-I, MHC-II, CD86, CD54 and CCR-7). (f) PET/CT images of tumor-bearing mice and excised tumors after treatment of unlabeled and non-pulsed DCs (1), unlabeled DCs pulsed with LLC lysates (2), labeled and non-pulsed DCs (3), and labeled DCs pulsed with LLC lysates (4). (g) Monitoring of cytotoxic activity of splenocytes from tumor-bearing mice with bioluminescence. LLC/effluc cells were used as target cells. Data are means \pm s.d. ( $N=7$ mice) $\left({ }^{*} P<0.05\right)$. CT, computed tomography; DC, dendritic cell; LLC, lung carcinoma; PET, positron emission tomography; Rle-AuNP, radionuclide-embedded gold nanoparticle.

(1.6-200 pм) and radioactivity of the RIe-AuNPs (Figure 2d). Since stability of the radionuclides on particles in a biological system is critical for sensitive and stable bioimaging over a long period, the stability of the radio-labeled RI-AuNPs (or RIe-AuNPs) in human serum was examined. Cleaved radionuclides appeared rapidly for the RI-AuNPs, that is, within $30 \mathrm{~min}$ (Figure 2e(1)). In contrast, the RIe-AuNPs showed only slight changes in the radio TLC, even after $24 \mathrm{~h}$ at $37^{\circ} \mathrm{C}$, indicating the excellent stability of the radio labels in the RIe-AuNPs because of the Au shell (Figure 2e(2)).

The effect of RIe-AuNP labeling on biological functions of DCs The RIe-AuNPs were used to label DCs to visualize their migration into the lymphatic system in real time. To achieve this goal, the effects of cellular labeling of the RIe-AuNPs on the cell viability, as well as the biological functions of the DCs were first investigated since these are critical factors for efficient cancer immunotherapy and imaging applications. The cellular uptake efficiency of the RIe-AuNPs on the DCs is dependent on the concentration of the RIe-AuNPs as shown in Figure 3a; the DCs became darker as the concentration of RIe-AuNPs increased (1.0-4.0 nM). A strong PET signal could be observed from the RIe-AuNP-labeled DCs (Figure $3 \mathrm{~b}(2)$ ). The optimum concentration of RIe-AuNPs and incubation time were found to be $2.0 \mathrm{~nm}$ and $3.0 \mathrm{~h}$, respectively (Supplementary Figure S3).

More importantly, the RIe-AuNPs should remain inside the DCs for quantitative and long-term tracking of the DCs. ${ }^{14}$ Analysis of the radioactivity of the RIe-AuNPs in the DCs over time showed a gradual decrease of the radioactivity. However, the RIe-AuNPs maintained more than $60 \%$ of the initial radioactivity inside the cells even after 3 days, indicating the excellent stability of the radio-labeled RIe-AuNPs in the DCs because of efficient protection by the Au shell 

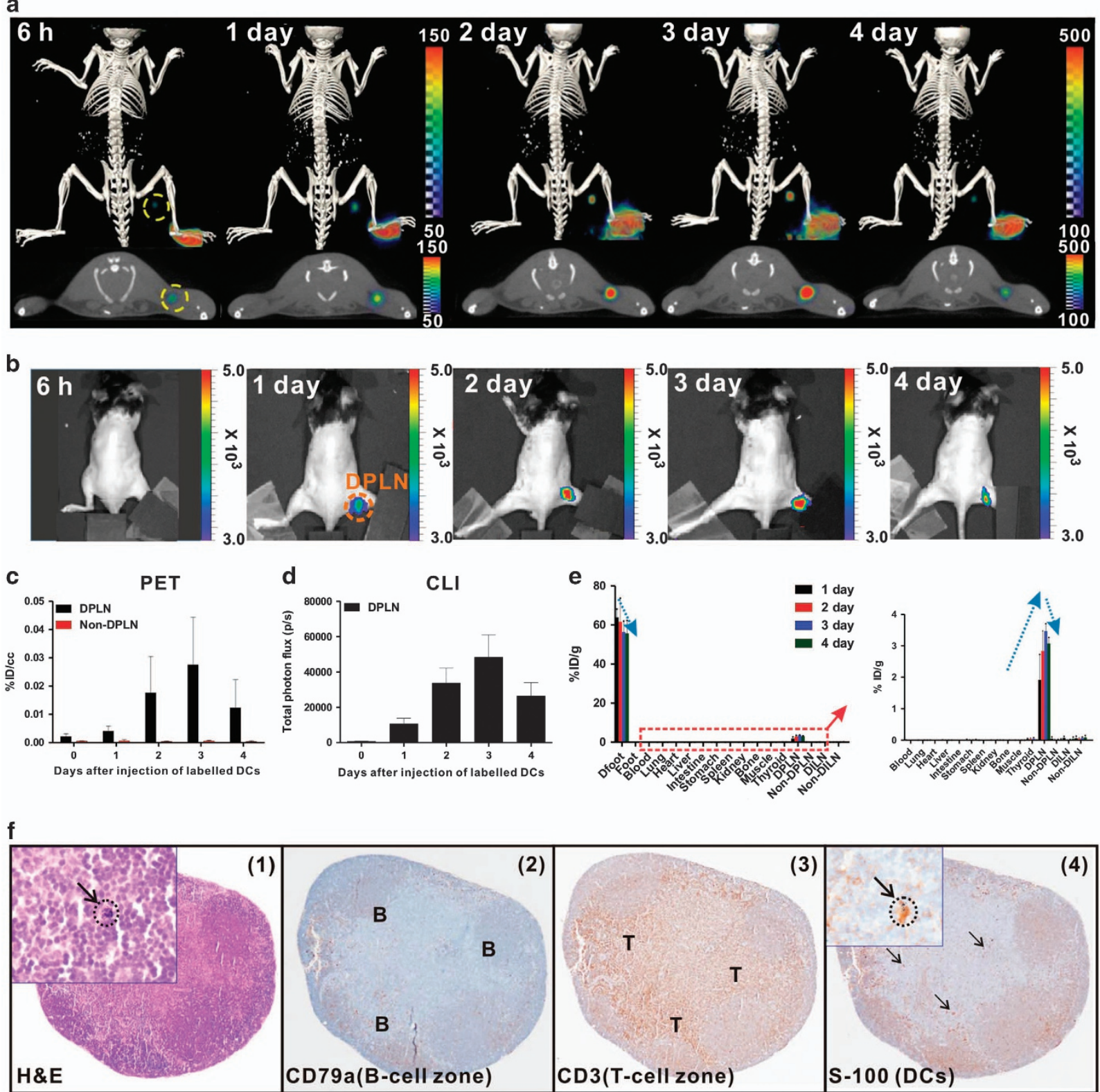

(2)
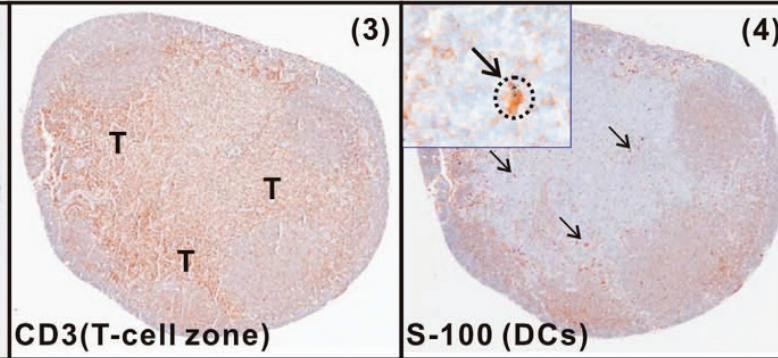

Figure 4 Time-dependent PET/CT, CLI, biodistribution and histology study. (a) Time-dependent three-dimensional-PET/CT images (upper) and axial PET/CT images (bottom). The yellow circle indicates the draining popliteal lymph nodes (DPLNs). (b) Time-dependent CLI images. The orange circle indicates the DPLNs. (c, d) Regions of interest for analysis of DPLNs and non-DPLNs in PET/CT and CLI imaging. Data are means \pm s.d., $n=5$. (e) Biodistribution of labeled DCs in whole organs after injection through the footpad. The red box indicates the magnified data to clearly show radioactivity changes in DPLNs. \%ID/g, percentage injected dose per gram. (f) Histological images of DPLN stained with H\&E (1), CD79a-specific antibody staining for the B-cell zone (2), CD3-specific antibody staining for the T-cell zone (3) and S100-specific antibody staining for DCs (4) (the black circle and arrow indicate Rle-AuNPs). Data are means \pm s.d. $(N=5)$. CT, computed tomography; H\&E, hematoxylin and eosin; PET, positron emission tomography; Rle-AuNP, radionuclide-embedded gold nanoparticle.

(Figure 3c). On the contrary, RI-AuNPs in DCs showed a rapid decrease of radioactivity inside DCs even after short periods of time ( $3 \mathrm{~h}$ ) because of no protective layer (Supplementary Figure S4).

The cell viability test showed a few differences between the labeled DCs and unlabeled DCs at all concentrations of the RIe-AuNPs (1.0-4.0 nm) over $48 \mathrm{~h}$ (Figure 3d). Moreover, the RIe-AuNPs did not induce apoptosis in the DCs (Supplementary Figure S5). The expression of phenotype markers, such as CD11c, MHC I, MHC II, CD86, CD54 and CCR7, related to adoptive T-cell immune responses did not differ regardless of RIe-AuNP labeling as shown in Figure $3 e$ and Supplementary Figure S6. The levels of several cytokines, the cell migration and antigen uptake capacities were not altered by RIe-AuNP uptake in the DCs (Supplementary Figure S7).

Anti-tumor immune responses of RIe-AuNP-labeled DCs

More importantly, we further examined the anti-tumor immune responses caused by the RIe-AuNP-labeled DCs in mice model with murine LLCs. ${ }^{26-28}$ To create a DC-based cancer vaccine capable of generating LLC-associated antitumor immunity, the DCs were pulsed with whole lysates of LLC cells, as shown in Supplementary 
Figure S8. Unlabeled and non-pulsed DCs, unlabeled DCs pulsed with LLC lysates, labeled and non-pulsed DCs and labeled DCs pulsed with LLC lysates were compared (Figures $3 \mathrm{f}-\mathrm{g}$ ). Antitumor effects were determined via caliper measurement and ${ }^{18} \mathrm{~F}-$ fludeoxyglucose $\left({ }^{18} \mathrm{~F}-\mathrm{FDG}\right)$ PET/CT imaging. ${ }^{18} \mathrm{~F}-\mathrm{FDG}$ can be used to monitor cancer glucose metabolism and is a surrogate for cell proliferation. ${ }^{29,30}$ The results show that tumor growth was effectively suppressed in mice immunized with unlabeled or labeled DCs pulsed with LLC lysates (Figure $3 f(2,4)$ ) but not in mice immunized with unlabeled or labeled DCs not pulsed with LLC lysates (Figure $3 f(1,3)$ ). Interestingly, the mice immunized with labeled DCs pulsed with LLC lysates exhibited the smallest tumor size, indicating strong anti-tumor activity of the DCs labeled with RIeAuNPs (Figure 3f(4), Supplementary Figure S9). To further determine the relationship between the antitumor immunity and the killing activity of cytotoxic T-lymphocyte cells, a cytotoxic assay using enhanced firefly luciferase-expressing LLC cells (LLC/effluc as a target) was performed by monitoring via bioluminescent imaging at an effector to target ratio of 10:1. Consistent with the findings from in vivo therapy, the luciferase activity in the splenocytes of mice immunized with the pulsed DCs (Figure $3 g(2,4)$ ) was lower than that in splenocytes of mice immunized with non-pulsed DCs (Figure $3 \mathrm{~g}$ $(1,3))$. Furthermore, the slight increase of the killing activity of cytotoxic $\mathrm{T}$ lymphocytes in mice immunized with the labeled DCs pulsed with LLC lysates (Figure $3 g(4)$ ) was consistent with the results of the smallest tumor size in mice (Figure $3 f(4)$ ). Taken together, these results suggest that labeling the DCs with RIe-AuNPs does not adversely affect the antitumor immunity of the DCs. In fact, increased antitumor activity was observed, although the exact mechanism underlying this enhanced antitumor immunity has not yet been elucidated. It is believed that the enhanced antitumor immunity originates from the stimulated immune response of the DCs, mediated by the RIe-AuNPs, which requires more detailed future investigation. ${ }^{31-33}$
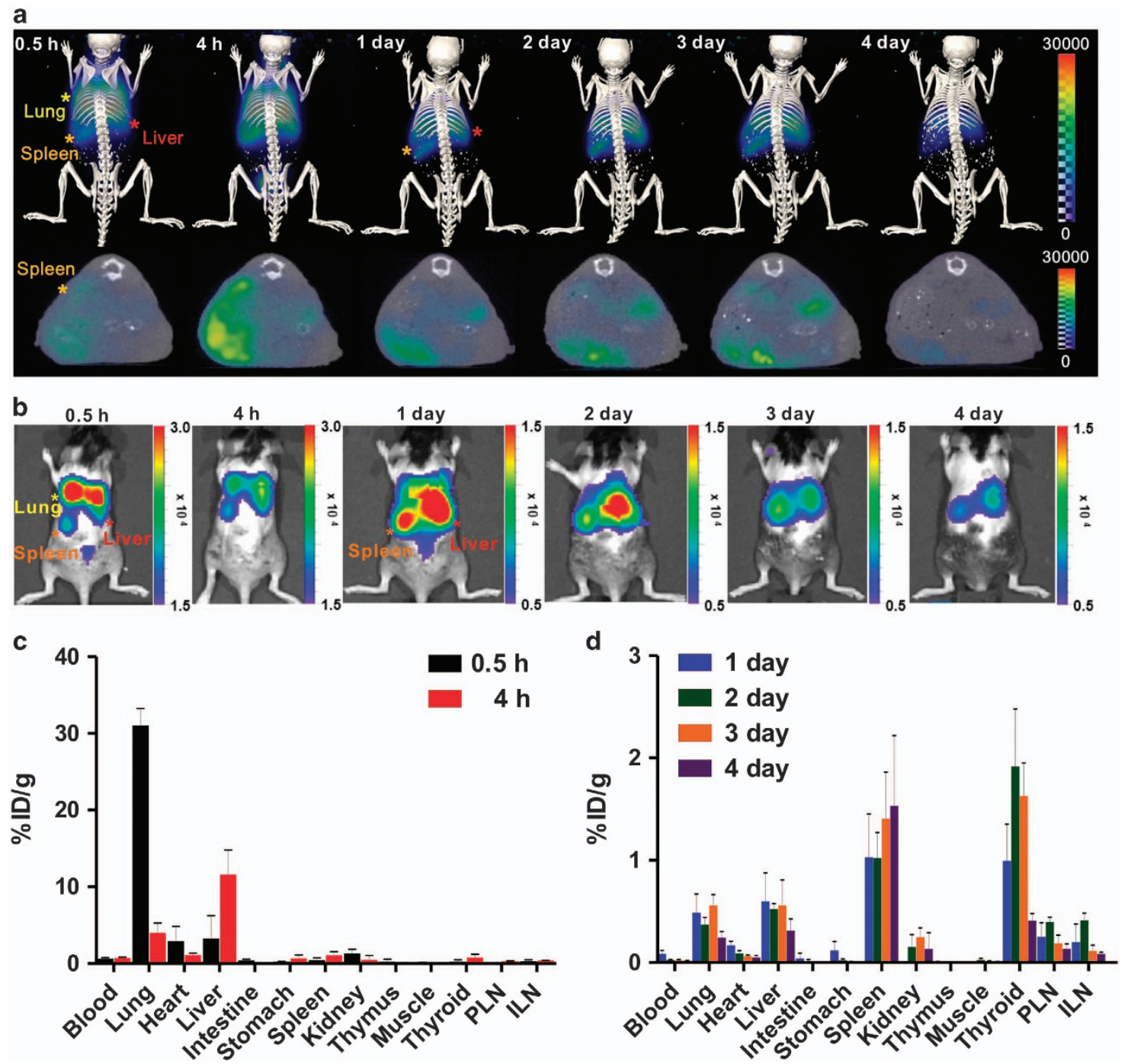

Figure 5 Time-dependent PET/CT, Cerenkov luminescence images and biodistributions of labeled DCs injected i.v. (a) Three-dimensional PET/CT images (top) and axial imaging (bottom). Yellow star: lung; red star: liver; orange star: spleen. (b) Cerenkov luminescence images were acquired using an optical imaging system (IVIS Lumina III). (c, d) Biodistributions of labeled DCs in mice (obtained at $0.5 \mathrm{~h}$ (black), $4 \mathrm{~h}$ (red), 1 day (blue), 2 days (green), 3 days (orange) and 4 days (purple) after i.v. injection of labeled DCs). CT, computed tomography; DC, dendritic cell; ILN, inguinal lymph node; PET, positron emission tomography; PLN, popliteal lymph node. Data are means \pm s.d. $(N=5)$. 


\section{Tracking of DC migration to the draining lymph nodes by} PET and CLI

The potential efficacy of the RIe-AuNPs as an in vivo imaging agent for DC tracking was evaluated using combined PET/CT and CLI imaging, as well as biodistribution study (see Supplementary Figure S10). DCs labeled with the RIe-AuNPs were s.c. injected into the footpad of mice to track migration of the DCs to the DPLNs. ${ }^{34-36}$ PET/CT imaging demonstrated highly selective migration of the labeled DCs to the DPLNs as early as $6 \mathrm{~h}$ post injection, with peak migration at day 3; the radioactive signals declined on day 4 (Figure 4a). Although most of the labeled DCs remained in the injected footpad, the labeled DCs were mainly found at the DPLNs because of the intrinsic nature of DCs. ${ }^{37}$ In contrast with the present technique, typical imaging methods for monitoring the migration of DCs to draining lymph nodes using either NIR fluorescent nanoparticles or MR imaging require a longer accumulation time (at least 12 or $24 \mathrm{~h}$ post transfer) to clearly visualize the DPLNs. Although CLI cannot be used to visualize the migration of labeled DCs to the DPLNs $6 \mathrm{~h}$ post transfer because of the lower sensitivity of optical imaging relative to PET, the CLI-based images also clearly showed migration of the DCs to the DPLNs, consistent with PET/CT imaging (Figure $4 \mathrm{~b}$ ). The strong correlation between the time-dependent changes of the PET signal and the intensity of the CLI signal indicate the strong potential of the RIe-AuNPs as a new optical imaging agent (Figures $4 \mathrm{c}$ and $\mathrm{d}$ ). The results of the biodistribution study were also highly consistent with the combined PET/CT imaging and CLI data (Figure 4e). Most of the DCs (55-60\%) remained at the site of injection (footpad); $2-3.5 \%$ of the DCs migrated to the DPLNs. Localization of the labeled DCs in the DPLNs was further confirmed by histological evaluation (Figure $4 \mathrm{f}(1)-(4))$. Histological analysis of the DPLNs clearly showed B-cell zones stained with anti-CD79a-specific antibodies (Figure $4 \mathrm{f}(2)$ ) and T-cell zones stained with anti-CD3-specific antibodies (Figure $4 \mathrm{f}(3)$ ). Notably, representative immunohistochemical evaluation of the DPLNs revealed the presence of S-100 (DC-specific marker)-positive DCs labeled with RIe-AuNPs (Figure $4 \mathrm{f}(4)$ ), mostly the within T-cell zones but not in the B-cell zones; these DCs contained dark brown particles (Figure $4 \mathrm{f}(4)$, inset). These results indicated that the DCs actively migrated toward the T-cell zone of the DPLNs. ${ }^{38}$

\section{Quantitative comparison between PET and CLI imaging}

The systemic biodistribution of the labeled DCs after i.v. injection was investigated to fully evaluate the potential of the RIe-AuNPs for combined PET/CT and CLI imaging (see Figure 5). The DCs labeled with RIe-AuNPs show clear localization in the lung, liver and spleen, even $0.5 \mathrm{~h}$ post transfer, and the labeled DCs could be clearly detected at day 4 (Figure $5 \mathrm{a}$ ). Even though several reports have demonstrated the distribution of DCs into the lungs, spleen and liver using various imaging modalities, ${ }^{39,40}$ the sensitive detection of localized DCs in the spleen as early as $0.5 \mathrm{~h}$ post transfer was not possible because of the low sensitivity of the previous imaging agents. Accumulation of radioactive iodine in the thyroid was not observed because of the excellent stability of the radio-labeling system utilizing embedding in the Au shell. In vivo CLI imaging also showed strong optical signals in the lung, liver and spleen $0.5 \mathrm{~h}$ post transfer, where the imaging quality was equivalent to that of the PET/CT images (Figure 5b). Typically, it is difficult to detect migrated cells in deep tissues, such as the lungs, spleen and liver, using optical imaging modalities due to depth limitations. However, in vivo CLI imaging with the RIe-AuNPs clearly revealed localization of the DCs in the deep tissues within short time spans (that is, 0.5 and $4 \mathrm{~h}$ ), demonstrating the strong potential of the RIe-AuNPs as a dual modal (nuclear and optical) imaging platform.
Because of higher spatial resolution, low-cost and high-throughput imaging capability of CLI compared with PET, CLI is expected to be a promising imaging modality. ${ }^{15,16,34}$ Consistent with in vivo PET/CT imaging, the biodistribution data clearly showed DCs in the lungs within $0.5 \mathrm{~h}$ after transfer, with subsequent rapid localization in the liver and spleen (Figures $5 \mathrm{c}$ and $\mathrm{d}$ ).

\section{CONCLUSION}

In summary, RIe-AuNPs were developed as a highly sensitive and stable nuclear and optical imaging agent. Synthesis of the RIe-AuNPs utilizes simple and straightforward DNA-based radio-labeling chemistry and additional $\mathrm{Au}$ shell formation strategies, leading to high radiosensitivity and excellent in vivo stability. Uptake of the RIe-AuNPs by DCs does not induce adverse effects on the biological functions of DCs, and the RIe-AuNP-labeled DCs exhibit strong and enhanced antitumor immunity. The strong radiosensitivity of the RIe-AuNPs $\left(0.2 \mathrm{mg} \mathrm{kg}^{-1}\right)$ facilitates sensitive and long-term monitoring of DC migration to draining lymph nodes. Interestingly, 100 DCs labeled with RIe-AuNPs could be imaged in living mice with PET because of strong and stable radiosensitivity (Supplementary Figure S11). Furthermore, the RIe-AuNPs are promising CLI-based optical imaging agents, comparable with that of PET in terms of sensitivity and penetration depth. ${ }^{15,16}$ Together, these results highlight the prospective of RIe-AuNPs as a new multimodal imaging platform for nuclear imaging and optical imaging applications.

\section{CONFLICT OF INTEREST}

The authors declare no conflict of interest.

\section{ACKNOWLEDGEMENTS}

This work was supported by the National Research Foundation of Korea (NRF-2013R1A1A1061387), KU-KIST research fund, a National Research Foundation of Korea (NRF) grant funded by the Korean Government (MEST, 2009-0078234), the National Nuclear R\&D Program through the National Research Foundation of Korea (NRF), funded by the Ministry of Education, Science and Technology (No. 2012M2A2A7014020), a grant from the Korea Health Technology R\&D Project, Ministry of Health \& Welfare, Republic of Korea (A111345), the Medical Cluster R\&D Support Project of Daegu Gyeong-buk Medical Innovation Foundation, and a National Research Foundation of Korea (NRF) Grant funded by the Korean Government (MSIP) (2014R1A1A1003323). This work was also supported by the National Research Foundation of Korea (NRF) grant funded by the Korea government (MSIP) (No. 2009-0078222, 2009-0078234), a grant of the Korea Health technology R\&D Project through the Korea Health Industry Development Institute (KHIDI), funded by the Ministry of Health \& Welfare, Republic of Korea (Grant No. HI16C1501), National Nuclear R\&D Program through the National Research Foundation of Korea (NRF) funded by the Ministry of Education, Science and Technology (No. 2012M2A2A7014020), a grant from the Medical Cluster R\&D Support Project through the Daegu-Gyengbuk Medical Innovation Foundation (DGMIF), funded by the Ministry of Health \& Welfare (Grant No. HT13C0002), BK21 PlusKNU Biomedical Convergence Program, Department of Biomedical Science, Kyungpook National University, National Research Foundation of Korea (NRF) grant funded by the Korea Government (MSIP) (No. 2014R1A1A1003323), a grant of the Korea Health Technology R\&D Project through the Korea Health Industry Development Institute (KHIDI), funded by the Ministry of Health \& Welfare (Grant No. HI15C0001), Radiation Technology R\&D program through the National Research Foundation of Korea funded by the Ministry of Science, ICT \& Future Planning (NRF-2012M2A2A7013480), and the National Research Foundation of Korea (NRF) grant funded by the Korea government (MSIP) (No. NRF-

2015M2A2A7A01045177). 
1 Boisselier, E. \& Astruc, D. Gold nanoparticles in nanomedicine: preparations, imaging, diagnostics, therapies and toxicity. Chem. Soc. Rev. 38, 1759-1782 (2009).

2 Ghosh, P., Han, G., De, M., Kim, C. K. \& Rotello, V. M. Gold nanoparticles in delivery applications. Adv. Drug Deliver. Rev. 60, 1307-1315 (2008).

3 Bardhan, R., Lal, S., Joshi, A. \& Halas, N. J. Theranostic nanoshells: from probe design to imaging and treatment of cancer. Acc. Chem. Res. 44, 936-946 (2011).

4 Lim, D. K., Jeon, K.-S., Hwang, J.-H., Kim, H., Kwon, S., Suh, Y. D. \& Nam, J. M. Highly uniform and reproducible surface-enhanced Raman scattering from DNA-tailorable nanoparticles with 1-nm interior gap. Nat. Nanotechnol. 6, 452-460 (2011).

5 Morales-Avila, E., Ferro-Flores, G., Ocampo-García, B. E., De León-Rodríguez, L. M., Santos-Cuevas, C. L., García-Becerra, R., Medina, L. A. \& Gómez-Oliván, L. Multimeric system of $99 \mathrm{mTc}$-labeled gold nanoparticles conjugated to $\mathrm{c}[\mathrm{RGDFK}(\mathrm{C})]$ for molecular imaging of tumor alpha(v)beta(3) expression. Bioconjugate Chem. 22, 913-922 (2011).

6 Zhao, Y., Sultan, D., Detering, L., Cho, S., Sun, G., Pierce, R., Wooley, K. L. \& Liu, Y. Copper-64-alloyed gold nanoparticles for cancer imaging: improved radiolabel stability and diagnostic accuracy. Angew. Chem. 53, 156-159 (2014).

7 Sun, X., Huang, X., Yan, X., Wang, Y., Guo, J. \& Jacobson, O. Chelator-free (64)Cu-integrated gold nanomaterials for positron emission tomography imaging guided photothermal cancer therapy. ACS Nano 8, 8438-8446 (2014).

8 Harris, J. M. \& Chess, R. B. Effect of pegylation on pharmaceuticals. Nat. Rev. Drug Discov. 2, 214-221 (2003).

9 Palucka, K. \& Banchereau, J. Cancer immunotherapy via dendritic cells. Nat. Rev. Cancer 12, 265-277 (2012).

10 Ardavin, C., Amigorena, S. \& Reis E Sousa, C. Dendritic cells: immunobiology and cancer immunotherapy. Immunity 20, 17-23 (2004).

11 Randolph, G. J., Angeli, V. \& Swartz, M. A. Dendritic-cell trafficking to lymph nodes through lymphatic vessels. Nat. Rev. Immunol. 5, 617-628 (2005).

12 de Vries, I. J., Lesterhuis, W. J., Barentsz, J. O., Verdijk, P., van Krieken, J. H., Boerman, O. C., Oyen, W. J., Bonenkamp, J. J., Boezeman, J. B., Adema, G. J., Bulte, J. W., Scheenen, T. W., Punt, C. J., Heerschap, A. \& Figdor, C. G. Magnetic resonance tracking of dendritic cells in melanoma patients for monitoring of cellular therapy. Nat. Biotechnol. 23, 1407-1413 (2005).

13 Ahrens, E. T., Flores, R., Xu, H. \& Morel, P. A. In vivo imaging platform for tracking immunotherapeutic cells. Nat. Biotechnol. 23, 983-987 (2005).

14 Wu, C., Xu, Y., Yang, L., Wu, J., Zhu, W., Li, D., Cheng, Z., Xia, C., Guo, Y. \& Gong, Q. Negatively charged magnetite nanoparticle clusters as efficient MRI probes for dendritic cell labeling and in vivo tracking. Adv. Funct. Mater. 25, 3581-3591 (2015).

15 Xiang, J., Xu, L., Gong, H., Zhu, W., Wang, C., Xu, J., Feng, L., Cheng, L., Peng, R. \& Liu, Z. Antigen-loaded upconversion nanoparticles for dendritic cell stimulation, tracking, and vaccination in dendritic cell-based immunotherapy. ACS Nano 9, 6401-6411 (2015)

16 Culver, J., Akers, W. \& Achilefu, S. Multimodality molecular imaging with combined optical and SPECT/PET modalities. J. Nucl. Med. 49, 169-172 (2008).

17 Adonai, N., Nguyen, K. N., Walsh, J., Iyer, M., Toyokuni, T., Phelps, M. E., McCarthy, T., McCarthy, D. W. \& Gambhir, S. S. Ex vivo cell labeling with $64 \mathrm{Cu}$-pyruvaldehyde-bis (N4-methylthiosemicarbazone) for imaging cell trafficking in mice with positronemission tomography. Proc. Natl Acad. Sci. USA 99, 3030-3035 (2002).

18 Thorek, D. L. J., Robertson, R., Bacchus, W. A., Hahn, J., Rothberg, J., Beattie, B. J. \& Grimm, J. Cerenkov imaging_A new modality for molecular imaging. Am. J. Nucl. Med. Mol. Imaging 2, 163 (2012).

19 Robertson, R., Germanos, M. S., Li, C., Mitchell, G. S., Cherry, S. R. \& Silva, M. D. Optical imaging of Cerenkov light generation from positron-emitting radiotracers. Phys. Med. Biol. 54, N355-N365 (2009).

$20 \mathrm{Xu}$, Y., Liu, H. \& Cheng, Z. Harnessing the power of radionuclides for optical imaging: Cerenkov luminescence imaging. J. Nucl. Med. 52, 2009-2018 (2011).

21 Lutz, M. B., Kukutsch, N., Ogilvie, A. L., Rössner, S., Koch, F., Romani, N. \& Schuler, G. An advanced culture method for generating large quantities of highly pure dendritic cells from mouse bone marrow. J. Immunol. Methods 223, 77-92 (1999).

22 Hurst, S. J., Lytton-Jean, A. K. \& Mirkin, C. A. Maximizing DNA loading on a range of gold nanoparticle sizes. Anal. Chem. 78, 8313-8318 (2006).

23 Rosi, N. L., Giljohann, D. A., Thaxton, C. S., Lytton-Jean, A. K. R., Han, M. S. \& Mirkin, C. A. Oligonucleotide-modified gold nanoparticles for intracellular gene regulation. Science 312, 1027-1030 (2006).

24 Mirkin, C. A., Letsinger, R. L., Mucic, R. C. \& Storhoff, J. J. A DNA-based method for rationally assembling nanoparticles into macroscopic materials. Nature 382, 607-609 (1996).

25 Kim, Y.-H., Jeon, J., Hong, S. H., Rhim, W.-K., Lee, Y.-S., Youn, H., Chung, J. K., Lee, M. C., Lee, D. S., Kang, K. W. \& Nam, J. M. Tumor targeting and imaging using cyclic RGD-PEGylated gold nanoparticle probes with directly conjugated iodine- 125 . Small 7, 2052-2060 (2011).

26 Steinman, R. M. The dendritic cell system and its role in immunogenicity. Annu. Rev. Immunol. 9, 271-296 (1991).

27 Zhong, H., Han, B., Tourkova, I. L., Lokshin, A., Rosenbloom, A., Shurin, M. R. \& Shurin, G. V. Low-dose paclitaxel prior to intratumoral dendritic cell vaccine modulates intratumoral cytokine network and lung cancer growth. Clin. Cancer Res. 13, 5455-5462 (2007).

28 Tian, X., Zhu, M., Tian, Y., Ramm, G. A., Zhao, Y. \& Nie, G. A membrane vesicle-based dual vaccine against melanoma and Lewis lung carcinoma. Biomaterials 33 , 6147-6154 (2012)

29 Som, P., Atkins, H. L., Bandoypadhyay, D., Fowler, J. S., MacGregor, R. R., Matsui, K., Oster, Z. H., Sacker, D. F., Shiue, C. Y., Turner, H., Wan, C. N., Wolf, A. P. \& Zabinski, S. V. A fluorinated glucose analog, 2-fluoro-2-deoxy-D-glucose (F-18): nontoxic tracer for rapid tumor detection. J. Nucl. Med. 21, 670-675 (1980).

30 Kelloff, G. J., Hoffman, J. M., Johnson, B., Scher, H. I., Siegel, B. A., Cheng, E. Y., Cheson, B. D., O'shaughnessy, J., Guyton, K. Z., Mankoff, D. A., Shankar, L., Larson, S. M., Sigman, C. C., Schilsky, R. L. \& Sullivan, D. C. Progress and promise of FDG-PET imaging for cancer patient management and oncologic drug development. Clin. Cancer Res. 11, 2785-2808 (2005).

31 Solanki, A., Cheung, S.-T. D., Yin, P. T., Kapera, R., Chhowalla, M. \& Li, K-B. Axonal alignment and enhanced neuronal differentiation of neural stem cells on graphene-nanoparticle hybrid structures. Adv. Mater. 25, 5477-5482 (2013).

32 Han, J., Kim, B., Shin, J.-Y., Ryu, S., Noh, M., Woo, J., Park, J. S., Lee, Y., Lee, N., Hyeon, T., Choi, D. \& Kim, B. S. Iron oxide nanoparticle-mediated development of cellular gap junction crosstalk to improve mesenchymal stem cells' therapeutic efficacy for myocardial infarction. ACS Nano 9, 2805-2819 (2015).

33 Park, J., Kim, B., Han, J., Oh, J., Park, S., Ryu, S., Jung, S., Shin, J. Y., Lee, B. S., Hong, B. H., Choi, D. \& Kim, B. S. Graphene oxide flakes as a cellular adhesive: Prevention of reactive oxygen species mediated death of implanted cells for cardiac repair. ACS Nano 9, 4987-4999 (2015).

34 Noh, Y. W., Lim, Y. T. \& Chung, B. H. Noninvasive imaging of dendritic cell migration into lymph nodes using near-infrared fluorescent semiconductor nanocrystals. Faseb J. 22, 3908-3918 (2008).

35 Baumjohann, D., Hess, A., Budinsky, L., Brune, K., Schuler, G. \& Lutz, M. B. In vivo magnetic resonance imaging of dendritic cell migration into the draining lymph nodes of mice. Eur. J. Immunol. 36, 2544-2555 (2006).

36 Martelli, C., Borelli, M., Ottobrini, L., Rainone, V., Degrassi, A., Russo, M., Gianelli, U., Bosari, S., Fiorini, C., Trabattoni, D., Clerici, M. \& Lucignani, G. In vivo imaging of lymph node migration of MNP- and (111)In-labeled dendritic cells in a transgenic mouse model of breast cancer (MMTV-Ras). Mol. Imaging Biol. 14, 183-196 (2012)

37 Martín-Fontecha, A., Sebastiani, S., Höpken, U. E., Uguccioni, M., Lipp, M., Lanzavecchia, A. \& Sallusto, F. Regulation of dendritic cell migration to the draining lymph node: Impact on T lymphocyte traffic and priming. J. Exp. Med. 198, 615-621 (2003).

38 Cho, N. H., Cheong, T. C., Min, J. H., Wu, J. H., Lee, S. J., Kim, D., Yang, J. S., Kim, S., Kim, Y. K. \& Seong, S. Y. A multifunctional core-shell nanoparticle for dendritic cell-based cancer immunotherapy. Nat. Nanotechnol. 6, 675-682 (2011).

39 Creusot, R. J., Yaghoubi, S. S., Chang, P., Chia, J., Contag, C. H., Gambhir, S. S. \& Fathman, C. G. Lymphoid-tissue-specific homing of bone-marrow-derived dendritic cells. Blood 113, 6638-6647 (2009).

40 Kupiec-Weglinski, J. W., Austyn, J. M. \& Morris, P. J. Migration patterns of dendritic cells in the mouse. Traffic from the blood, and T cell-dependent and -independent entry to lymphoid tissues. J. Exp. Med. 167, 632-645 (1988).

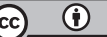

This work is licensed under a Creative Commons Attribution 4.0 International License. The images or other third party material in this article are included in the article's Creative Commons license, unless indicated otherwise in the credit line; if the material is not included under the Creative Commons license, users will need to obtain permission from the license holder to reproduce the material. To view a copy of this license, visit http:// creativecommons.org/licenses/by/4.0/

(C) The Author(s) 2016

Supplementary Information accompanies the paper on the NPG Asia Materials website (http://www.nature.com/am) 